RESENHA

Bookreview

\title{
TRANSFORMING MILITARY POWER SINCE THE COLD WAR: BRITAIN, FRANCE, AND THE UNITED STATES, 1991-2012
}

\author{
Marcus Vinícius Pinheiro Dutra Piffer ${ }^{2}$
}

O livro explora os processos de transformação dos exércitos dos Estados Unidos, do Reino Unido e da França ocorridos entre 1991 e 2012. Embora o título do livro cite a transformação do poder militar, os autores optaram por um recorte que abordasse apenas os exércitos por entenderem que o poder aéreo e naval foram apenas coadjuvantes em relação ao poder militar terrestre nos conflitos que ocorreram durante o período estudado.

Em sua Introdução, o livro explora a crise pela qual as forças militares dos paísesmembros da OTAN mergulharam após a queda do Muro de Berlim e o esfacelamento da União Soviética. Suas forças armadas, preparadas e equipadas para um combate de alta intensidade contra o Pacto de Varsóvia se encontraram repentinamente com um grande excesso de material, sem uma ameaça concreta e sem uma clara ideia de qual seriam as suas missões dali em diante. Dessa forma, se colocaram novos desafios a esses exércitos: para os Estados Unidos, o exército tinha como objetivo se manter à frente dos demais estados que se apresentassem como concorrentes e também fazer frente a oponentes não-

\footnotetext{
${ }^{1}$ FARRELL, T.; RYNNING, S.; TERRIFF, T. Transforming Military Power since the Cold War: Britain, France, and the United States, 1991-2012. Cambridge, UK: Cambridge University Press, 2013. ISBN: 9781107621442

${ }^{2}$ Major do Exército Brasileiro e mestre em Ciências Miltares pelo Instituto Meira Mattos da Escola de Comando e Estado-Maior do Exército. Email: pifferm@gmail.com
} 


\section{Conjuntura Austral}

estatais. Os países europeus visavam manter seus exércitos com capacidades próximas das norte-americanas e atender aos seus compromissos regionais e globais.

Os três exércitos estudados seguiram linhas mestras semelhantes em seus processos de transformação: a mudança de uma estrutura dedicada à guerra continental para uma estrutura expedicionária. Isso resultou na substituição de tropas blindadas por tropas mecanizadas mais leves e da organização em divisões de exército por forças modulares organizadas em escalões menores, como brigadas ou batalhões. Além disso, houve uma intensa "digitização" do campo de batalha e o aumento do emprego dos conceitos de guerra centrada em redes.

O primeiro capítulo trata das transformações ocorridas no Exército dos Estados Unidos. Uma característica desse período foi a restrição dos orçamentos. O processo de encolhimento do Exército americano, que já ocorria desde a década de 1980, se acentuou. O exército passou de uma estrutura com dezoito divisões para a atual, com dez divisões.

O alto-comando do exército americano se preocupou em realizar uma "evolução e não uma revolução", de modo a que os comandos subordinados aceitassem melhor as inovações. Uma questão recorrente nos Estados Unidos é o uso da tecnologia para melhorar a consciência situacional ou mesmo criar a "omnisciência" situacional. Dessa maneira se eliminaria o fog da guerra e a superioridade de informações substituiria a necessidade de grandes efetivos. Notou-se ao longo dos anos foi que a grande quantidade de informações era muito difícil de ser analisada e o que realmente interessava - as reais intenções do inimigo - permanecia desconhecido (MURRAY, 2009). O emprego massivo da tecnologia da informação se mostrou um salto muito grande e, talvez por isso, não atingiu as metas a que se propunha. A reorganização das unidades, teoricamente mais simples, foi efetivamente a indutora das transformações, tornando o exército mais ágil e modular.

O capítulo seguinte trata do Reino Unido. Todo o processo de transformação desse exército é regido por uma premissa básica: a "relação especial" entre Reino Unido e Estados Unidos. Dessa maneira, qualquer que fosse a transformação que fosse realizada, o seu resultado teria que ser um elevado grau de interoperabilidade com o exército americano. Porém, essa interoperabilidade apresenta dois grandes óbices culturais: o 


\section{Conjuntura Austral}

primeiro é o forte tradicionalismo do exército britânico, com uma cultura centrada na autoridade e no homem. Essa atitude não vê com bons olhos a estrutura menos hierarquizada e a troca de informações no sentido horizontal que ocorre na guerra centrada em redes. O outro é o natural ceticismo dos militares britânicos quanto à tecnologia.

A transformação do exército foi planejada sobre grandes projetos. Nenhum deles efetivamente atingiu seus objetivos. Durante todo o período, o ministério da defesa centralizou bastante as mudanças. Esse fato, aliado às grandes limitações orçamentárias, limitou o sucesso dos projetos. Mais recentemente, os comandantes das forças armadas foram colocados num patamar de autoridade equivalente ao do chefe do Estado-Maior Conjunto ${ }^{3}$ e estão com uma maior liberdade para gerir seus projetos e orçamentos.

O último capítulo trata do exército francês. Assim como ocorreu com os britânicos, a transformação francesa teve um resultado bastante diferente do que havia sido visualizado inicialmente. O catalisador para o início da transformação foi a Guerra do Golfo, em 1991. O governo determinou, nessa ocasião, que o contingente francês deveria ser composto exclusivamente por efetivos profissionais. Essa decisão expôs o despreparo francês para a campanha. O serviço militar obrigatório, um aspecto muito caro ao exército francês e que lhe conferiu vantagens em campanhas históricas, se mostrou inadequado, ao menos da maneira que estava sendo conduzido. O planejamento para a transformação foi fortemente baseado na tecnologia, mas dúvidas e controvérsias internas causaram um baixo comprometimento com esse processo. Os franceses se orgulham de sua capacidade de combater "no meio do povo". David Galula é um expoente nesse tipo de ambiente e sua obra ${ }^{4}$ inspirou a atual doutrina americana de contra-insurgência.

O exército francês foi efetivamente moldado pelas operações das quais participou nesse período - com óbvio destaque para o Afeganistão - e não pelos projetos que deveriam realizar essa transformação. Como a participação nessas campanhas foi relativamente modesta, a transformação não foi tão extensa como se planejara inicialmente.

\footnotetext{
${ }^{3}$ Este é um arranjo semelhante ao adotado no Brasil (N. do A.).

${ }^{4}$ Galula (1966)
} 


\section{Conjuntura Austral}

Ao concluir, os autores tratam principalmente da emulação realizada pelos britânicos e franceses para poder combater ao lado dos americanos. Este é um dos aspectos mais interessantes do livro, pois Farrell e Terriff, em estudo realizado uma década antes (FARRELL; TERRIFF, 2002), argumentavam que a emulação era um assunto pouco estudado por ser realizada quase que exclusivamente por países em desenvolvimento. Apesar de citarem os poderes aéreo e naval como coadjuvantes durante esse período, os autores citam, em diversas ocasiões, que as campanhas do Kosovo e da Líbia contribuíram para as transformações citadas. Ambas as campanhas, porém, foram conduzidas quase que exclusivamente por meios aéreos e navais. Durante o caso específico da campanha na Líbia, em 2011, a participação dos exércitos se resumiu quase que exclusivamente aos helicópteros de ataque empregados e ainda assim houve uma enorme diferença entre os procedimentos empregados por britânicos e franceses, refletindo assim os diferentes rumos tomados durante os processos de transformação ${ }^{5}$.

Os três exércitos estudados se tornaram menores, mais leves, tecnológicos e expedicionários. Apesar dessas linhas gerais comuns, nenhum dos programas de transformação implantados foi realizado da maneira que estava inicialmente previsto. Também se viu um processo de emulação conduzido por potências médias, de considerável poder militar, e que não foi bem sucedido por impeditivos culturais: o tradicionalismo britânico e a "crise de consciência" francesa em abandonar aspectos historicamente consolidados em seu exército.

Os autores demonstram claramente que cada processo de transformação é conduzido pelos imperativos culturais da nação e que quando os projetos tendem a fugir desse padrão, dificilmente lograrão o êxito desejado. O Exército Brasileiro atualmente conduz um processo de transformação baseado em projetos indutores, que guarda uma grande semelhança conceitual com os casos citados no livro, notadamente os dos exércitos britânico e francês. Essa característica torna a obra de Farrell, Rynning e Terriff de grande relevância para militares e estudiosos desse processo.

\footnotetext{
${ }^{5}$ Para as operações da aviação do exército francês, v. Ciolette (2012). Para a contrapartida britânica, v. Hoyle (2011) e Ripley (2012).
} 


\section{Conjuntura Austral}

\section{Referências}

CIOLETTE, M. R. Harmattan: A maioridade da ALAT. Pégasus, n. 18, jul. 2012.

FARRELL, T.; TERRIFF, T. (EDS.). The Sources of Military Change: Culture, Politics, Technology. Boulder, CO: Lynne Rienner Publishers, 2002.

GALULA, D. Teoria e prática da contra-rebelião. Rio de Janeiro: Edições GRD, 1966.

HOYLE, C. Libya: British Army details Apache's success. Disponível em: <http://www.flightglobal.com/news/articles/libya-british-army-details-apache39ssuccess-359298/>. Acesso em: 23 out. 2014.

MURRAY, W. Military Adaptation in War. Alexandria, VA: Institute for Warfighting Program, 2009.

RIPLEY, T. British Army Aviation in Action. South Yorkshire: Casemate Publishers, 2012.

Resenha recebida em 03 de novembro de 2014. Aprovada em $1^{\circ}$ de fevereiro de 2014. 